\title{
A DINAMICIDADE DE MODELOS ATRAVÉS DE ANIMAÇÕES PARA O ENSINO DE FÍSICA
}

\author{
THE DYNAMICITY OF MODELS THROUGH ANIMATIONS FOR TEACHING PHYSICS
}

\begin{abstract}
Antonio Xavier $\mathrm{Gil}^{1}$
Alexandre Souza da Silva ${ }^{2}$

RESUMO: Aulas expositivas com Modelos Físicos estáticos, pouco tem motivado os alunos para o entendimento dos fenômenos e conceitos dos conteúdos de Física. Neste sentido, Buscar Métodos e Técnicas que promovam a dinamicidade dos modelos Físicos, podem em muito contribuir para a motivação, reflexão e compreensão destes conteúdos. Para tal, desenvolvemos a nossa pesquisa em quatro momentos: I) Uma pesquisa exploratória para a composição do estado da arte sobre o emprego de animações e sobre a dinamicidade dos Modelos Físicos já disponíveis em trabalhos de outros autores; 2) Seleção de Métodos e Técnicas empregadas para a construção de Modelos Físicos dinâmicos; 3) Desenho metodológico para a construção e disponibilização do material instrucional com animações; 4) Aplicação da metodologia construída com animação em sala de aula. Esta Pesquisa tem as características de ser exploratória, investigativa, e descritiva, com abordagem qualitativa. Os resultados obtidos foram uma metodologia com utilização de animações no Power Point, para ser usada em sala de aula, ou assistidas em tablets, celulares, e notebooks, bem como, a melhoria das percepções dos estudantes sobre a visualização, identificação e compreensão dos fenômenos e conceitos físicos.
\end{abstract}

Palavras-chave: Tecnologia virtual. Modelos Físicos. Metodologia de Ensino.

ABSTRACT: Expositive classes with static Physical Models, has little motivated students to understand the phenomena and concepts of the physics contents. In this sense, searching for methods and techniques that promote the dynamics of physical model, can greatly contribute to the motivation, reflection and understanding of these contentes. To this end, we developed our research in four moments: I) An exploratory research for the composition of the state of the art on the use of animations ando $n$ the dynamics of the physical Models already available in works by Other authors: 2) Selection of Methods and Techniques used to build dynamic physical Models; 3) Methodological design for the construction and provisiono $f$ instructional material

\footnotetext{
I Graduado em Licenciatura em física, Engenharia Civil, língua e literatura inglesa pela Universidade Federal do Amazonas (UFAM). Mestrado em Física pela UFSCAR. Doutorado em Educação em Ciências e Matemática pela Universidade Federal de Mato Grosso (UFMT). Atualmente, é professor e pesquisador da Universidade Federal do Amazonas (UFAM). E-mail: xavier2oogxavier@gmail.com. ${ }^{2}$ Graduado em Licenciatura em Física pela Universidade Federal do Amazonas (UFAM), Professor e pesquisador de Física, participou de projetos de extensão e eventos nacionais, com trabalhos apresentados na área de educação.
} 
with animations; 4) Application of the methodology built with Animation in the classroom. This research has the characteristics of being exploratory, investigative, and descriptive, with a qualitative approach. The results obtained. The results obtained were a methodology with the use of animations in Power Point, to be used in the classroom, or assisted in tablets, cell phones, and notebooks, as well as, the improvement of the students' perceptions about the visualization, identification and understanding of the phenomena and physical concepts.

Keywords: Virtual technology. Physical Models; Teaching Methodology.

\section{INTRODUÇÃO}

Os modelos físicos que são apresentados em livros ou desenhados por professores em sala de aula, são interpretações simplificadas da realidade, que se destacam como um pequeno aspecto de todo o contexto ou fração desse conjunto, que em caso de complexidade divide-se em vários modelos, os mesmos servem para visualização e compreensão dos fenômenos físicos, porém são apresentados de forma estática, imóvel, tendo que ser idealizado como se tivesse movimento real, para sua compreensão. No entanto, muitos destes modelos dificultam a aprendizagem dos alunos, pois os mesmos não formulam no seu cognitivo uma conexão dos modelos com o cotidiano e o mundo ao seu redor, assim dispondo de uma física com metodologia tradicional que usufrui de um quadro branco, pincel e repetições de equações matemáticas, que desestimulam a criatividade e o envolvimento dos aprendizes.

Por outro lado, temos o avanço das tecnologias, que possibilitam utilizar recursos didático-pedagógicos inovadores no ensino, como, por exemplo, a animação, e como ferramenta a utilização do computador; que nos permite construir uma metodologia com modelos físicos dinâmicos, a qual discorremos nesta pesquisa, no intuito melhorar a visualização e percepção dos fenômenos e conceitos de Física. Estes modelos apresentados pelas animações, contrapõem-se aos modelos estáticos, como as figuras e desenhos, que em sua forma concebida são inertes, sem movimentos.

Então, com o uso de modelo dinâmico, com animação, os alunos tiveram uma melhoria na visualização e compreensão dos fenômenos e conceitos físicos, que foram debatidos em sala de aula e que estão presentes no cotidiano, podendo constituir-se em um recurso facilitador no processo de ensino-aprendizagem de Física, e como exemplo, 
citamos o trabalho de Gonçalves et al (2006) “Textos, animações e vídeos para o ensino-aprendizagem de física térmica no ensino médio" , cujo resultado mostrou que seu material pode servir como auxiliar em sala de aula, despertando interesse e compreensão dos assuntos tratados e, também, como fonte de consulta fora do ambiente escolar, para aprofundar o que aprenderam nas aulas.

De um modo geral temos um recurso simples, mas que facilita o entendimento dos fenômenos físicos, sendo apresentado pelos educadores na ministração de suas aulas, torna a interação do aluno com o material didático de animação, uma metodologia de ensino muito benéfica no processo ensino-aprendizagem. Assim, a elaboração da nossa metodologia foi baseada, inicialmente, nos textos e imagens dos livros didáticos e situações do cotidiano, para em seguida serem elaboradas de modo dinâmico, com o recurso de animações.

\section{FUNDAMENTAÇAO}

Com base nos estudos da Psicologia da Gestalt, podemos perceber que nosso

cérebro tenta organizar tudo que vemos e que são captados pelos sentidos. Então, a Gestalt organizou sete leis, que regem a nossa percepção, e que explicam como as pessoas veem as animações que foram criadas neste trabalho, e como o cérebro organiza essa ilusão de óptica, a qual é constituída por uma sequência de imagens estáticas, postas uma a uma em uma sequência de slides, que obedecem aos seguintes princípios: I) Semelhança; 2) Proximidade; 3) Continuidade; 4) Pregnância; 5) Fechamento; 6) Segregação; 7) Unificação.

Tendo como base os estudos da Gestalt, discorremos sobre cada uma destas leis, de modo a dar suporte ao desenvolvimento deste trabalho.

I) Semelhança: Nesta lei, o cérebro tenta organizar as figuras que são semelhantes, colocando-as em uma sequência ordenada, conforme a aparência das imagens, veja o exemplo das Figuras 2 e 3. 
Figura 2: Imagem que demonstra semelhança entre as partes

\section{0

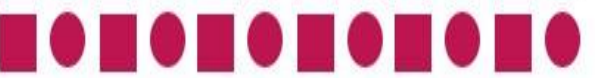 101010101010 П0п1010п10п0}

Fonte: Psicologia da Aprendizagem, Autor: Juliane Paprosqui. (Adaptado pelo autor).

$\mathrm{Na}$ Figura 2, a maioria das pessoas visualiza colunas de círculos e colunas de quadrados e não fileiras que intercalam círculos e quadrados, e é isso que o cérebro faz, organiza conforme as aparências geométricas das figuras.

Figura 3: Print da tela inicial da animação "Radiação de um corpo negro"

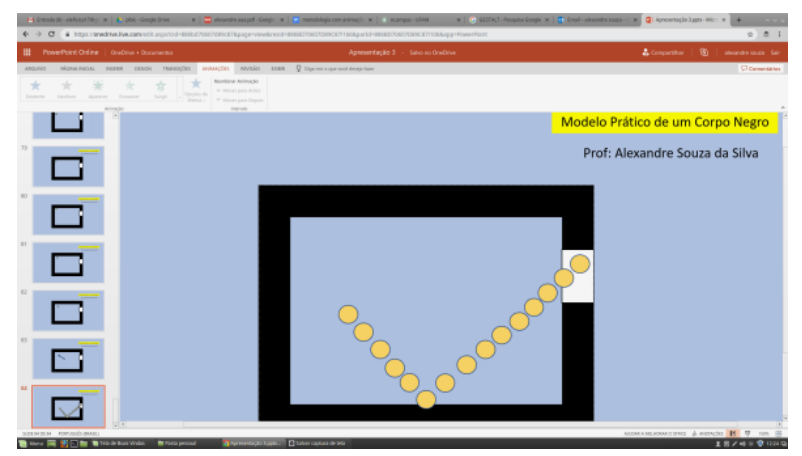

Fonte: Autores

No caso da animação da radiação do corpo negro, Figura 3, tem bolinhas para representar uma onda (radiação), e estas apresentam-se estáticos na figura, entretanto, serão assistidas na animação por uma sequência de slides, onde a nossa retina capta cada imagem e vai sobrepondo-as, dando a ilusão óptica de que elas estão em movimento, e sendo refletidas pelas paredes da cavidade quadrada. 
2) Proximidade: $O$ cérebro tenta agrupar diversas formas geométricas, ou seja, figuras que são semelhantes entre si, e que estão mais próximas umas às outras, temos como exemplo a Figura 4.

Figura 4: Figuras geométricas que empregam a lei da proximidade.

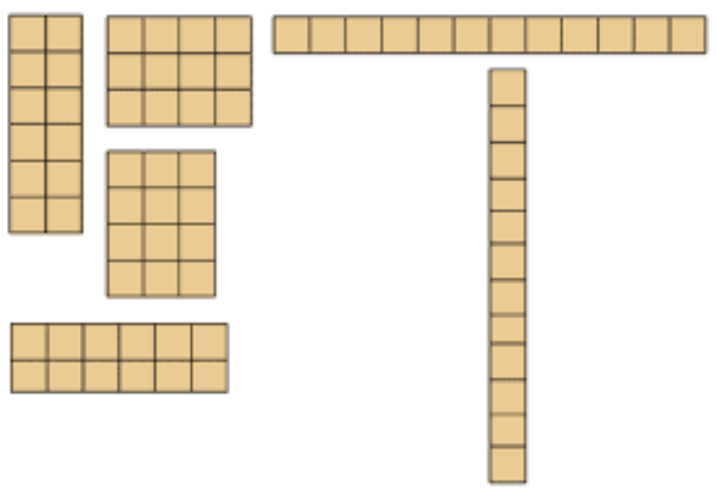

Fonte: Autores

3) Continuidade: $O$ cérebro tenta dar continuidade a algumas coisas, mesmo que a forma da figura ou do objeto não pareça completo, o cérebro tende a completar, dando um sentindo para a figura ou objeto em questão. Como exemplos, temos a figura 5.

Figura 5: Imagem que contempla o exemplo de continuidade da psicologia da Gestalt.

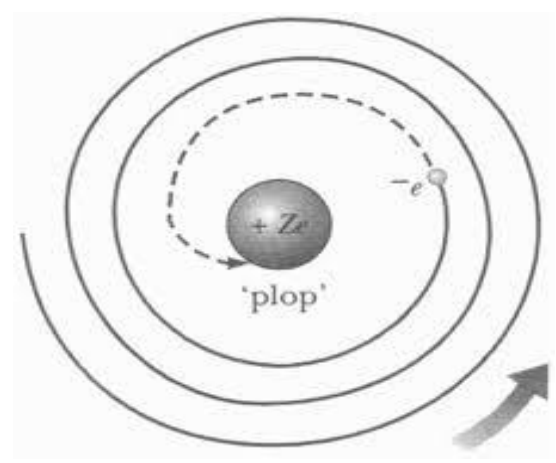

Fonte: Autores 
4) Pregnância: O cérebro tenta simplificar o que está sendo visto, quanto mais simples a figura (forma) mais facilmente podemos associar a algo que lembramos, como por exemplo, temos a Figura 6.

Figura 6: Imagem que contempla o exemplo de fechamento da psicologia da Gestalt



Fonte: Autores

6) Segregação: É a capacidade cerebral de identificar e destacar formas (imagens) separadas de um todo, ou seja, formar imagens com a união de duas ou mais figuras. Assim, não podemos observar determinada forma, se apenas olharmos para cada parte do todo separadamente, então é preciso visualizar o conjunto inteiro, fazendo com que o cérebro consiga captar todo o contexto, para formar a imagem global.

7) Unificação: É a tendência que o cérebro tem de unir as partes que estão separadas ou muito próximas com o fechamento, na unificação o cérebro tende a integrar diversas figuras, inclusive figuras que não são semelhantes, para formar algo que possivelmente a pessoa já tenha visto em algum lugar ou diariamente no seu cotidiano.

De que maneira estas leis podem ser utilizadas na educação? Quais suas contribuições para o campo educacional? Que recursos podem ser utilizados com o envolvimento destes princípios? Com a utilização destes princípios, o educador é capaz de elaborar metodologias que atiçam as percepções dos aprendizes, principalmente o 
campo visual, utilizando recursos, como, por exemplo, o exposto neste trabalho, animação.

Neste sentido, o professor pode desenvolver metodologias que motivem e agucem às percepções dos alunos, principalmente no campo visual, com a utilização de animações. Porém, para que a aprendizagem se torne significativa, e desperte o interesse pelo conhecimento, não temos uma "fórmula mágica" à nossa disposição. $O$ que sabemos de forma geral, é que, os métodos de aprendizagem, que são mais centrados nos alunos, e que tentam utilizar os canais do sentido visual, são os que mais favorecem esse despertar que almejamos.

Em termos de aprendizagem mecânica, podemos citar Ausubel, que se colocou contrário a aprendizagem mecânica, onde a informação é armazenada de maneira arbitrária, e quando o aluno faz uso deste tipo de aprendizagem, o conhecimento se distribui pelo seu cognitivo, sendo armazenado na memória à curto prazo, e portanto, não formando subsunçores mais permanentes, os que constituem a memória à longo prazo, que é a mais desejada na aprendizagem.

Ausubel define os conceitos de subsunçores como sendo os conhecimentos específicos já existentes na estrutura cognitiva do indivíduo, de modo que a aprendizagem se torna significativa quando a nova informação (conhecimento), no qual será construída, a partir da mediação do professor, se relaciona aos conhecimentos específicos, denominados subsunçores. Para Ausubel, "O conhecimento prévio do aluno é a chave para a aprendizagem significativa" (AUSUBEL, 1982).

Este recurso didático-pedagógico de animação, segundo artigo de Castilho e Ricci (2006), cujo tema é: "O uso de animações como elemento motivador de aprendizagem”, está muito longe de ser uma aprendizagem mecânica, decorativa, e de memorização; ao invés disso, a utilização das mesmas, evidenciam a realidade do aluno, pois as animações dispõem de uma visão dinâmica do fenômeno físico presente no dia a dia, tendo em vista que o aluno além de poder visualizar, também poderá formular suas hipóteses e coletar suas próprias conclusões acerca da animação. 
Assim, o uso desse modelo com animação, aplicadas junto às metodologias de ensino, permitem aos alunos terem uma aprendizagem melhor, pois eles conseguem relacionar as animações, apresentadas pelo professor, com seus respectivos subsunçores específicos, que estão presentes em seus cognitivos, ou seja, as novas informações ancoradas pelos conhecimentos prévios.

As animações, para os estudantes, podem servir como auxiliar na construção do conhecimento, despertando interesse e compreensão do assunto, além disso, podem ser utilizadas dentro ou fora do ambiente escolar.

Conforme o artigo de Gonçalves et al (2008), cujo tema é "Textos, Animações e Vídeos para o Ensino-Aprendizagem de Física Térmica no Ensino Médio”, o recurso didático empregado teve a pretensão de conceder ao docente uma ferramenta de apoio, que possibilitou o desenvolvimento dos conteúdos de maneira mais dinâmica, despertando no aluno a motivação para aprender.

Lev Vygotsky afirma que qualquer indivíduo precisa de um “outro" para existir

como ser, ou seja, ele não é um único elemento, necessitando do outro para se relacionar, se comunicar, e principalmente pensar.

O processo de interação do indivíduo com o meio é que pode resultar em aprendizagem, ou seja, quando o docente utiliza as animações como apoio (recurso didático), ele está mediando o conhecimento e permitindo que haja uma interação, tanto professor/aluno/animação como professor/animação/aluno, e isto possibilita que o conteúdo seja construído, diferentemente de uma aula convencional onde o aluno apenas recebe a informação.

Utilizar-se deste modelo dinâmico, da animação, contribui para que o aluno possa extrair as suas próprias conclusões acerca dos fenômenos físicos.

\section{METODOLOGIA}

No primeiro momento, tivemos a fase de levantamentos de dados sobre as obras de outros autores, que se deu através de pesquisas na internet, nos livros didáticos, em jornais, revistas, vídeos, programas de TV e outras fontes mais. 
Com a utilização do computador e seus softwares, o docente pode se libertar de uma aula tradicional e monótona, para empregar uma aula mais criativa, motivadora e que desperte nos alunos, a curiosidade e o desejo de aprender, conhecer e de fazer novas descobertas.

As animações neste trabalho foram elaboradas no software Power Point. A Priori foi construída uma única imagem, com as ferramentas de desenho já existentes no software, que simulasse a situação de determinado fenômeno Físico no mundo real ou abstrato. Depois, copiamos esta primeira imagem para um segundo slide, aonde através de pequenas modificações na posição do desenho, vamos obtendo outros slides, que ao serem exibidos em sequência nos dão a impressão de animação, desta forma obtêm o movimento desejado dos corpos, simulando o fenômeno em questão.

O Power Point é munido de ferramentas para desenho de formas geométricas variadas, permitindo ainda a inserção de som, vídeo e imagens, além de controle de tempo e de exposição dos slides, o que pode ser aproveitado para provocar a sensação de dinamicidade e/ou movimento das imagens.

Feita a seleção dos assuntos, chegou-se na etapa da construção das animações. Então, para cada assunto, criou-se uma animação. Desta forma, no total foram elaboradas 20 animações. Em seguida, criou-se um blogger, onde elas foram disponibilizadas no site: https://alefisicar7.blogspot.com/. para facilitar as suas visualizações, tanto por professores quanto por alunos, e para poderem ser utilizadas dentro ou fora do ambiente escolar. Finalmente, criou-se uma sequência didática para a aplicação da primeira animação, que serviu de modelo para as demais.

No segundo momento construímos um questionário, no intuito de analisar a interação dos alunos com a tecnologia. Diante desta análise, criou-se a sequência didática proposta, escolheu-se os conteúdos a serem ministrados, e por último, elaborou-se os planos de aula.

Com a criação das animações desse projeto, foi desenhado uma possível metodologia de ensino, para aplicação em sala de aula, com uma sequência didática, que seguiu uma teoria de aprendizagem, dada pelos teóricos: Lev Vygotsky, David 
Ausubel, e, também, pela linha de pensamento da psicologia da Gestalt. Como, por exemplo, para explicar o Átomo de Borh, foi criada a seguinte animação no Power Point, Figura 7.

Figura 7 - Animação do Modelo de átomo de Bohr.

MODELO DE ÁTOMO DE BOHR

Fonte: Autores

Que obedeceu a seguinte sequência didática:

I) Avaliação inicial sobre o tema; 2) Exploração Dialogada sobre o Assunto; 3) Apresentação da Animação; 4) Debate e Discussão sobre o tema; 5) Avaliação Final sobre o Assunto.

A aplicação da metodologia com animação ocorreu em duas turmas do terceiro ano do Ensino Médio, com um total de 80 alunos, todos na faixa de i6 à 18 anos de idade, em uma Instituição de Ensino público, dirigida pelo Estado. Optou-se neste trabalho por não identificar os nomes próprios dos sujeitos participantes, bem como o endereço e nome da escola, assegurando-se assim a privacidade de todos os envolvidos por questões éticas. Assim, cumprindo com os requisitos éticos do comitê de ética de pesquisa.

A implementação do projeto PIBIC ocorreu num período de três meses, uma vez por semana, e em um dia agendado. A duração foi de I (uma) hora de aplicação para cada turma, no total de 12 (doze) horas.

Seguindo-se a sequência didática já definida, foram elaboradas duas atividades avaliativas que envolveram o uso das animações, e que serviram para coletar 
dados da pesquisa. A primeira atividade foi composta de um simples questionário, com quatro questões dissertativas, a respeito do conteúdo explanado em sala de aula, sobre um Modelo Quântico para as Radiações Eletromagnéticas, disponível em: https://alefisicar7.blogspot.com/.

A segunda atividade proposta, foi para relacionar especificamente a compreensão e análise de uma determinada animação. Após o desenvolvimento da sequência didática proposta, utilizando-se a metodologia com animações, e com o conteúdo "Efeito Fotoelétrico", disponível em: https://alefisicar7.blogspot.com/.

Construiu-se uma segunda animação, sobre o fenômeno do Efeito Fotoelétrico, Figura 8, com um formato diferente da apresentada em sala de aula.

Figura 8 - Efeito Fotoelétrico (modelo 2)

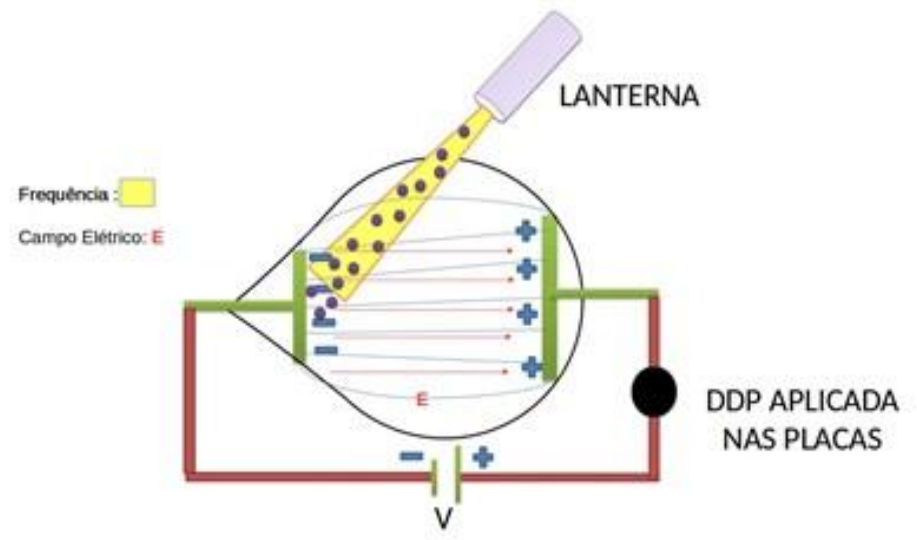

Fonte: Autores

A duração desta segunda atividade, assim como a da primeira, teve um tempo de 40 (quarenta) minutos, onde os alunos tiveram que produzir um texto, com quantas linhas fosse preciso, ou seja, não foi determinado um número mínimo ou máxima de linhas ou palavras, deixando a critério de cada aluno, para escrever sobre o que eles estavam compreendendo da animação que lhes foi apresentada na atividade.

E outras animações mais foram criadas. Um exemplo disso, é como mostra a Figura 9, sobre o fenômeno de eletrização por contato. 
Figura 9: Print da tela inicial da animação, "eletrização por contato" em vídeo.



Fonte: Autores- Software Power Point

A figura io tem por finalidade explicar sobre circuitos elétricos.

Figura ıo: Print da animação "Circuitos Elétricos”, a fim de explicar o conteúdo, diferença de potencial.

$$
\Delta \mathrm{V}=\mathrm{Vb}-\mathrm{Va}
$$
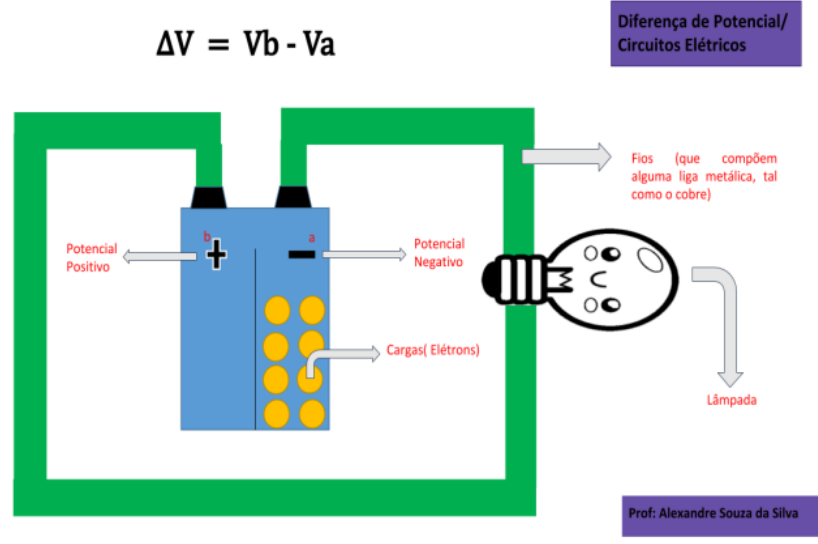

Fontes: Autores

A Figura to exibe a passagem de corrente elétrica, ou seja, dos elétrons devido a uma diferença de potencial (ddp). O presente material possibilita a visualização dos portadores de cargas, passando em um fio condutor de modo a fazer ligar a lâmpada, sendo que esta tem uma resistência associada a ela, permitindo a dissipação de energia 
em forma de luz (ondas eletromagnéticas), porém, este modelo virtual não seria possível observar no mundo real, quando tratamos de partículas elementares onde se encontram num sistema microscópico; no cotidiano, os alunos poderiam apenas observar os componentes do circuito elétrico, tais como, os fios, o gerador, a lâmpada, conseguiriam visualizar a lâmpada acendendo, mas não poderiam visualizar o fluxo de corrente elétrica.

\section{RESULTADOS E ANÁLISES}

Conforme a metodologia proposta pelo projeto, algumas análises referentes a revisão bibliográfica foram levantadas, acerca do uso de animações, nas metodologias de ensino. A utilização de metodologias com animações, dispõem de recursos tecnológicos presente no cotidiano dos alunos, tais como, os celulares, notebook, tablets, entre outros. Utilizando tais recursos percebemos que estes cooperam para o processo ensino-aprendizagem, pois a transposição dos conteúdos de Física para animações, permite aos alunos a visualização dos fenômenos físicos de situações do cotidiano, dos conceitos, possibilitando associar as grandezas envolvidas e as correlações entre elas.

Com base nas reflexões acerca do uso de animações, foi elaborada uma sequência didática, que utilizou este material didático na aplicação de uma metodologia de ensino.

No sentido de verificar se a utilização de animações, no ensino de Física, contribui com a melhoria do processo de ensino-aprendizagem, neste momento foram elaborados o plano de ensino e os planos de aula, bem como os instrumentos de coleta de dados, para serem aplicados em sala de aula, e posteriormente serem analisados.

A Priori foi construído o questionário I, no intuito de analisar a interação dos alunos com a tecnologia, através dos resultados, detectamos que todos os alunos já tiveram contato com a tecnologia, e muitos destes, 80\% utilizam-na diariamente, especificando por meio dos celulares, tablets, computadores e notebooks, como evidência os Gráficos I e 2. 
Gráfico I - Contato e utilização de tecnologias pelos alunos

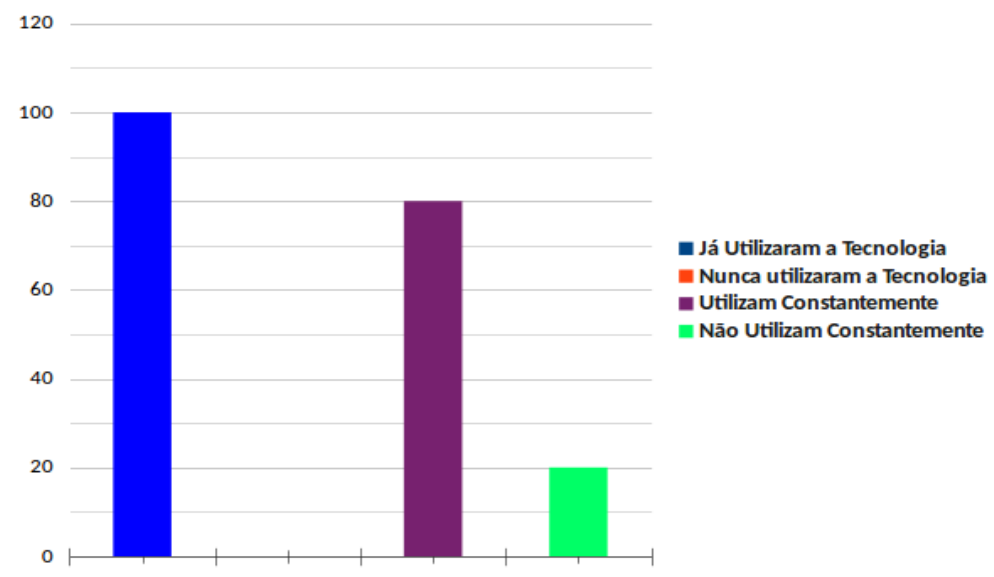

Fonte: Autores

Gráfico 2 - Percentual dos recursos tecnológicos mais utilizados pelos alunos.

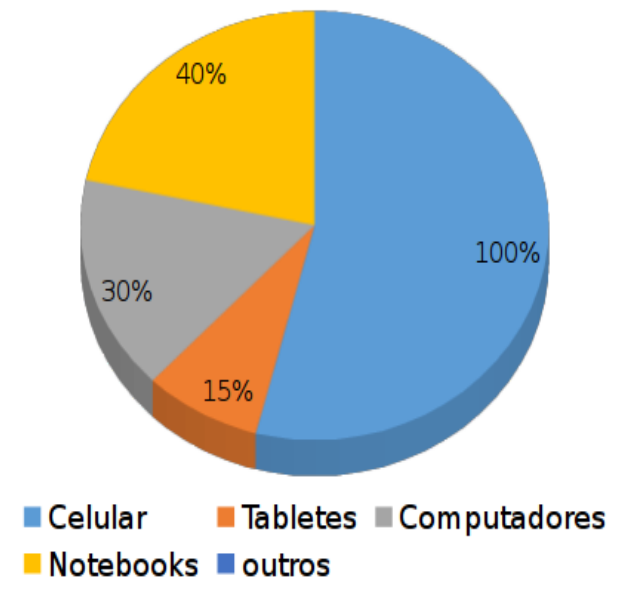

Fonte: Autores

Os assuntos selecionados foram de Física Moderna e Física 3, os temas de Física moderna foram de certa forma "desafiadores", no sentido de que a grande maioria dos professores não os abordam no Ensino Médio.

A primeira atividade proposta visou identificar se o aluno conseguia compreender o conteúdo "Modelo quântico para as radiações eletromagnéticas", de forma significativa, mediada pelo educador e utilizando a metodologia com animações. 
Desta maneira, o índice de aprendizagem dos alunos, acerca dos conteúdos, foi avaliado por graus de compreensão do assunto, dispondo de quatro níveis de intensidade; ruim, regular, bom e ótimo.

Destacamos aqui o significado de cada um desses níveis, que são:

I) Ruim (o à $<2,5$ ): Muito aquém do padrão esperado;

2) Regular (2,5 ̀̀ <5,0): Desenvolve de maneira insatisfatória dentro do padrão esperado, ou seja, padrão ainda não satisfatório no critério avaliado;

3) Bom (5,o à $<7,5)$ : dentro do padrão esperado;

4 Ótimo (7,5 à Io): Acima do padrão esperado, supera expectativas, demonstrando padrão de excelência no critério avaliado.

Assim, sendo a primeira atividade, de acordo com o Gráfico 3, temos que os resultados foram satisfatórios, com 60\% dos alunos com índice bom; 15\% ótimo; e 25\% regular. Nesta atividade os índices de alunos para o nível ruim foram de o\%, ou seja, não houve índice ruim.

Gráfico 3 - índice percentual de aprendizagem, dos alunos, na atividade I.



Fonte: Autores

Podemos visualizar, no Gráfico 3, que mais da metade dos alunos conseguiram compreender o assunto abordado ( $60 \%$ bom $+15 \%$ ótimo e $25 \%$ regular), e até mesmo relacioná-lo com o cotidiano.

David Ausubel cita que, se o aluno não estiver disposto a aprender, o mesmo não conseguirá ir além de compreender o conteúdo, quanto mais fazer parte do processo ensino-aprendizagem, deste modo, para ele, o aluno deixa de ter uma 
aprendizagem significativa e passa a ter uma aprendizagem mecânica, de acordo com Marco Antonio, "De maneira recíproca, independentemente de quão disposto para aprender estiver o indivíduo, nem o processo nem o produto de aprendizagem serão significativos, se o material não for potencialmente significativo.”(MOREIRA, 2oII, pg. 156).

Considerando a taxa de alunos no índice regular, destacamos que estes, após a mediação do conhecimento, utilizando a metodologia com animações, possivelmente não revisaram o conteúdo e não utilizaram as animações como apoio, no processo de aprendizagem, de forma que não concretizaram o assunto proposto, haja vista que após o desenvolvimento da construção do conhecimento, os alunos obtiveram um intervalo de tempo, de uma semana, com a finalidade de que eles pudessem revisar o conteúdo, entrar no ambiente virtual, blogger, e visualizar quantas vezes fosse necessária a animação, apesar de que ela já tenha sido apresentada em sala de aula.

A criação desta metodologia que utiliza animações como recurso didático, não afirma que a mesma servirá para todos os alunos, i.e., para todos os tipos de aprendizagem, de acordo com Cerqueira (2000), o autor descreve que cada aluno tem um tipo de aprendizagem, ou seja, um modo de aprender, haja vista que todos os indivíduos são diferentes uns dos outros, portanto, é evidente que alguns alunos se adaptem a esta metodologia de ensino, enquanto outros possam não se adaptar ou levar um tempo maior na consolidação da informações e construção do conhecimento, no que envolve os processos cognitivos.

Neste sentido, a disponibilização das animações, por meio do blogger, permite que o aluno possa visualizá-las fora do ambiente escolar, e utilizá-las como apoio no processo ensino-aprendizagem, pois as animações podem ser vistas e/ou pausadas quantas vezes o aluno achar necessário, favorecendo assim a compreensão e assimilação do Fenômeno Físico.

Logo, para a primeira atividade, e pelos resultados apresentados, concluiu-se que o uso de metodologias que utilizam animações, contribuiu para o processo ensinoaprendizagem. 
A segunda atividade, relaciona-se especificamente com a compreensão de uma determinada animação. Após a aplicação da metodologia com animações, no desenvolvimento da sequência didática proposta, sobre o conteúdo "Efeito Fotoelétrico", foi construído uma segunda animação com um formato diferente da apresentada em sala de aula, porém abordando o mesmo conteúdo e raciocínio, do exposto em aula.

As mudanças feitas na animação que contemplou a segunda atividade, não quebraram o vínculo da animação com o conteúdo ministrado. Portanto, quando nos referimos às mudanças no formato da animação, destacamos que estas são, por exemplo, na cor, na paisagem, no tamanho e até mesmo ao utilizar um outro objeto, mas que tivessem o mesmo objetivo, que foi explicar de forma visual e dinâmica, por meio deste recurso, o mesmo conteúdo exposto em aula. $\mathrm{O}$ critério de pontuação da avaliação, seguiu o mesmo contexto da primeira atividade, ruim, regular, bom e ótimo.

Temos então os resultados obtidos da segunda avaliação, com 50\% dos alunos em ótimo, 40\% bom, I0\% regular e o\% ruim. Diante desta coleta de dados, plotamos o seguinte Gráfico 4 .

Gráfico 4 - índice percentual de aprendizagem, dos alunos, na atividade 2.

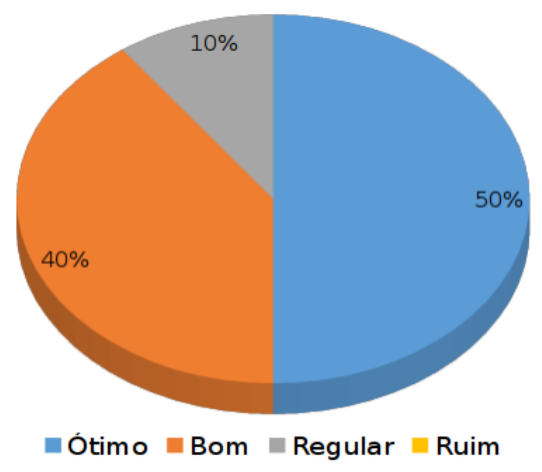

Fonte: Autores

$\mathrm{Na}$ análise do Gráfico 4 comparando com o Gráfico 3, temos um aumento de 35\% no nível ótimo, ou seja, os alunos utilizaram as animações como apoio para construção do conhecimento, de forma a terem uma aprendizagem significativa, no que tange a relacionar os subsunçores presentes no cognitivo, com as animações e 
conceitos abordados em sala de aula, de maneira que este recurso auxiliou para estruturar e firmar o novo conhecimento.

Diante desta análise, temos que $90 \%$ dos alunos ficaram dentro do padrão esperado, ou seja, estão no nível bom e ótimo, estes consolidaram no seu cognitivo os assuntos que foram debatidos em sala de aula, e conseguiram relacionar as animações com o tema abordado. Sendo que a maioria das animações apontam fenômenos que acontecem no mundo real, ou seja, em situações problemas do dia a dia, notamos que este recurso contribui para uma aprendizagem significativa.

O recurso didático proposto serve de apoio no processo ensino-aprendizagem, contribuindo ao educando, conforme a teoria de Vygotsky, o avanço do desenvolvimento potencial para o desenvolvimento real.

Segundo David Ausubel, quando o aluno aprende significativamente, o assunto é armazenado na sua memória de longa duração, ou seja, este conteúdo não é esquecido e mesmo que venha a ser, sua reaprendizagem é imediata.

Portanto, os resultados da segunda atividade nos mostram que, se comparado com os da primeira atividade, um maior índice de alunos que fizeram parte do processo de aprendizagem, ou seja, a construção do conhecimento, além de evidenciar que, a utilização de animações, contribuem para que o aluno assimile e visualize os conceitos físicos através deste recurso.

A terceira atividade, contempla analisar as percepções dos alunos acerca do uso de determinada animação, ou seja, como eles interagem com este recurso, quais as vantagens e desvantagens, se eles conseguiram concatenar a animação com o conteúdo, entre outras características.

Nessa atividade, podemos extrair inúmeras conclusões acerca das porcentagens advindas de cada pergunta, porém é notório que o uso de animações no ensino de Física é visto com bons olhos pela grande maioria dos educandos, de maneira que o uso desta ferramenta ajuda aos alunos a terem uma maior assimilação dos conteúdos e consequentemente uma aprendizagem mais significativa. 


\section{CONSIDERAÇÕES FINAIS}

Estamos em uma era, onde a tecnologia está cada vez mais se tornando presente na vida dos seres humanos, e nada mais justo do que utilizar esta ferramenta a favor da educação, para contribuir de forma significativa, no processo Ensino-Aprendizagem, as novas tecnologias de informação e conhecimento (TDIC ou TIC) se mostram como um apoio/recurso de uma importância notória para o ensino.

A modificação dos métodos de aprendizagem, proporcionada pelas técnicas de animação, traz à sala de aula uma forma inovadora de ensino e aprendizagem, que por sua vez, foge àquilo que normalmente é tratado na escola. Tais processos, utilizam as TDIC como suporte, para o ensino, utilizando uma metodologia inovadora e possibilitando a inclusão digital do aluno, e até mesmo dos educadores.

Através do uso de animações procurou-se facilitar a interpretação dos fenômenos físicos de difícil compreensão ou abstração, além de reproduzir virtualmente experiências difíceis ou impossíveis de realizar na prática, por serem muito perigosas, lentas ou muito rápidas e até mesmo por não termos condições nenhuma de realizarmos estas experiências na escola devido à falta de laboratório nela.

$\mathrm{O}$ uso de animações por computador permitiu proporcionar ao aluno um ambiente que retomou, em parte, o experimento didático de laboratório. A percepção visual animada do fenômeno interferiu de forma positiva no aprendizado, os resultados alcançados constataram que a inclusão digital é necessária a todos da sociedade que se encontram aquém da realidade desejada e necessária para a vivência na sociedade da informação.

A modificação dos métodos de aprendizagem, proporcionada pelas técnicas de animação, traz à sala de aula uma forma de ensino e aprendizagem, que por sua vez, foge àquilo que normalmente é tratado na escola. Tais processos, utilizam as TDIC como suporte, para o ensino, utilizando uma metodologia inovadora e possibilitando a inclusão digital do aluno, e até mesmo dos educadores.

O propósito deste trabalho não se trata de dar uma receita de como ter alunos ativos no processo de aprendizagem, ou em como ter uma aprendizagem significativa, e sim, auxiliar os docentes para que estes processos, com a utilização de metodologias 
que utilizem o uso de animações, sejam evidenciados. Porém é importante que cada docente se sinta bem, aplicando qualquer tipo de metodologia. São inúmeras as metodologias disponíveis, logo, encontrar aquela em que permite uma melhor comunicação, relação, a fim de ajudar aos alunos a terem um melhor aprendizado, será a mais benéfica para o processo ensino-aprendizado.

Portanto, podemos concluir que, a metodologia elaborada com animações tem grande potencial para contribuir com a melhoria do atual panorama da educação na escola, tornando o conhecimento mais estimulante, acessível e compreensível para os alunos, uma vez que a utilização desse tipo de metodologia promove a interação da teoria com a prática do cotidiano, proporcionando uma aprendizagem significativa para os alunos.

\section{REFERÊNCIAS}

AlCOFORADO, M. G.; PADILHA, M. A. S. 2010. Educando com Design de Animação. In: Congresso Brasileiro de Pesquisa e Desenvolvimento em Design, 9, São Paulo, 13 a 16 out. 2010. Anais do $9^{-}$Congresso Brasileiro de Pesquisa e Desenvolvimento em

Design. São Paul Figura 7 - Animação do Modelo de átomo de Bohr.

o: Blucher e Universidade Anhembi Morumbi. p. 2712-2724.

AUSUBEL, D. P. A Aprendizagem Significativa: A Teoria de David Ausubel. São Paulo: Moraes, 1982.

CASTILHO, M. I.; RICCI, T. F. O uso das animações como elemento motivador de Aprendizagem, 2006. Disponível em:< https://lume.ufrgs.br/bitstream/handle/I0I83/622/ooo558278.pdf?sequence =I\& is Allo wed $=y>$. Acesso em: 05/03/2021 as I7h3omin.

GONÇALVES, L. J.; VEIT, E. A.; SILVEIRA, F. L. Textos, animações e vídeos para o ensino-aprendizagem de física térmica no ensino médio, v.I, 2006. Disponível em:< https://lume.ufrgs.br/bitstream/handle/I0183/621/ooo558274.pdf?sequence $=$ I\& isAllo wed =y>. Acesso em: 05/03/2021.

MOREIRA, M. A. Teorias de Aprendizagem, $2^{\circ}$ edição, editora EPU, 2011. 
Tecnologia Educacional: Mitos e possibilidades na sociedade tecnológica, V. 29, 2000. VIGOTSKY, L. S; LURIA, A. R.; LEONTIEV, A. N.. Linguagem, desenvolvimento e aprendizagem, $14^{\circ}$ Edição. 